\title{
Biosynthesis of monolignols. Genomic and reverse genetic approaches
}

\author{
Richard A. Dixon* \& M. S. Srinivasa Reddy \\ Plant Biology Division, Samuel Roberts Noble Foundation, 2510 Sam Noble Parkway: Ardmore, OK, 7340), USA; \\ ${ }^{*}$ Author for correspondence (Tel: +1-580-224-6601; Fax: + 1-580-224-6692; E-mail: radixon@noble.org)
}

Key words: expressed sequence tag, genetic manipulation, lignification, Medicago truncatula, monolignol

\begin{abstract}
The biosynthesis of monolignols is one of the most studied pathways of plant natural product biosynthesis. However, the pathway has recently undergone considerable revision, and it would appear that our understanding of the exact routes for synthesis of the building blocks of lignin and lignans is still not fully understood. Early studies of in vitro enzyme specificity failed to appreciate the catalytic promiscuity of some of the enzymes of the monolignol pathway, and the evolving model of a metabolic grid for monolignol biosynthesis may fail to appreciate the possible extent of metabolic channeling within the pathway. New approaches to the study of monolignol biosynthesis include genomics, advanced cellular imaging techniques, and transgenic manipulation. This article summarizes the use of these approaches to gain a better understanding of the operation of a complex metabolic pathway.
\end{abstract}

\section{Introduction}

Lignin is a complex polymer of hydroxylated and methoxylated phenylpropane units, linked via oxidative coupling (Boudet et al., 1995), and serves as a major structural component of secondarily thickened plant cell walls. It imparts mechanical strength to plant stems and trunks, and hydrophobicity to waterconducting vascular elements. Because of the negative effects of lignin on paper pulping and forage quality, there is considerable interest in genetic manipulation to alter the quantity and/or quality of the lignin polymer (Whetten and Sederoff, 1991; Boudet and GrimaPettenati, 1996; Dixon et al., 1996; O'Connell et al., 1998). Many lignans originate from the monolignol coniferyl alcohol, and genetic modification of lignans is also of interest in relation to potential human health benefits, since grain seed lignans such as secoisolariciresinol and matairesinol are converted by intestinal microflora to enterolactone and enterodiol, estrogenic compounds with potentially positive effects in relation to cancer and cardiovascular disease (Mazur and Adlercreutz, 1998). These approaches require an understanding of the various enzymatic and regulatory processes involved in monolignol biosynthesis and lignin polymerization and deposition.
Dicotyledonous angiosperm lignins contain two major monomer species, termed guaiacyl (G) and syringyl (S) units. $G$ units are characterized by a single methoxyl substituent on the aromatic ring and arise from coniferyl alcohol, whereas $S$ units are di-methoxylated and arise from sinapyl alcohol (Figure 1). Lignin from monocotyledonous plants also contains a significant proportion of $\mathrm{H}$ units derived from coumaryl alcohol. The monomeric units in lignin are joined through at least five different types of linkages (Davin and Lewis, 1992), and polymerization proceeds via free radical reactions initiated by the enzymes peroxidase and laccase (Sato et al., 1993; Bao et al., 1993). The mechanisms that determine the relative proportions of the linkage types in a particular lignin polymer are currently unknown. However, lignin composition is developmentally programmed, both temporally and spatially (Terashima et al., 1993).

Although the exact mechanisms underlying the initiation, growth and termination of the lignin polymer remain to be determined, much more is known concerning the biosynthetic pathways leading to the individual monolignols. Although studies on monolignol biosynthesis have a long history (Lewis et al.. 1999), the past two years have seen major re-evaluations of the pathway (Dixon et al., 2001: Humphreys and 


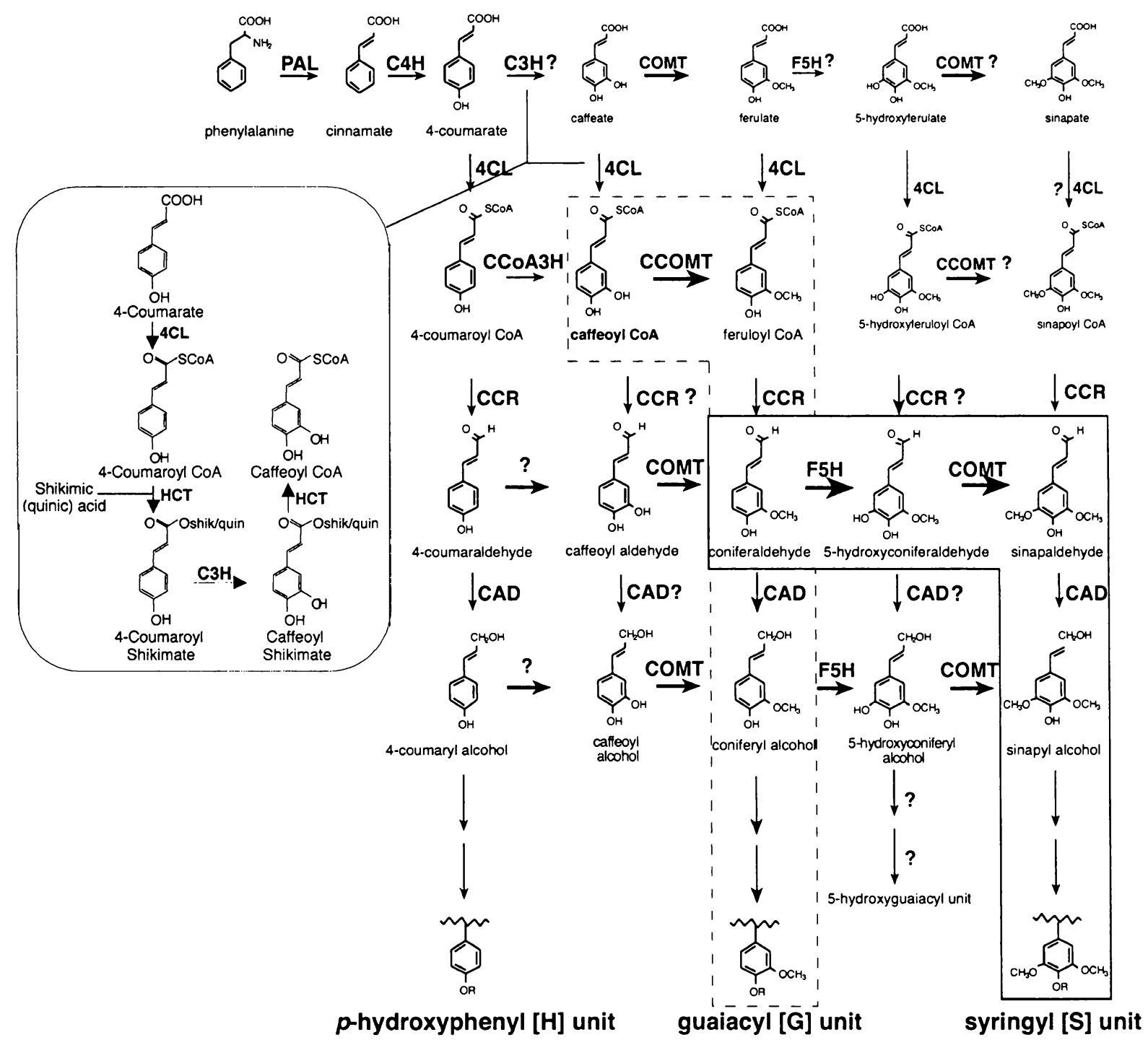

Figure 1. Scheme showing the proposed pathways leading to the biosynthesis of guaicayl and syringyl monolignols. This scheme incorporates data from in vitro enzymatic studies in several different plant species. and may not represent the actual in viro pathway in any specific species. See text for details of the various enzymes.

Chapple, 2002), in part based on the results of reverse genetic approaches aimed at modification of lignin content and composition in model species. This chapter reviews the development of our ideas on biosynthetic pathways leading to monolignols, and assesses the impact of new genomics technologies and genetic manipulation approaches on our understanding of lignin biosynthesis.

\section{The monolignol pathway - Evolution of ideas}

Until recently, our understanding of the ring substitution reactions of monolignol biosynthesis had been largely based on substrate specificity studies in vitro with available assumed substrates. Such an approach has formed the basis of much of the discipline of biochemistry, where reactions shown to occur in vitro are generally assumed to also function in vivo. However, in the case of monolignol biosynthesis, it is now clear that some of the enzymes are relatively promiscuous, and some substrates initially believed to be of 
physiological significance may not be actual pathway intermediates in vivo.

Figure I presents a diagrammatic summary of the monolignol pathway as currently perceived. It was initially thought that the successive ring hydroxylations and $O$-methylations in monolignol biosynthesis took place at the level of hydroxycinnamic acids (Neish, 1968). For example, caffeic acid $O$-methyltransferase (COMT) was first shown to convert caffeic acid to ferulic acid, and was later shown also to convert 5hydroxyferulic acid to sinapic acid (Davin and Lewis, 1992). Two challenges to this view of monolignol formation came with the realizations that, firstly, there appeared to be an alternative pathway for methylation at the coenzyme A ester level involving caffeoyl CoA $O$-methyltransferase (Ye et al.. 1994). This enzyme is more closely related to mammalian catechol (OMT than to plant COMT at the DNA sequence level (Joshi and Chiang, 1998). Second, the enzyme known as ferulate 5-hydroxylase ( $\mathrm{F} 5 \mathrm{H}$ ) has only low activity with ferulic acid as substrate, a finding that questioned the operation of the pathway at the free acid level. It was subsequently demonstrated that $\mathrm{F5H}$ was much more active with coniferaldehyde as substrate, and that 5-hydroxyconiferaldehyde was a preferred substrate for COMT (Humphreys et al., 1999; Osakabe et al., 1999). Inhibition of COMT-mediated methylation of caffeic acid in vitro by 5-hydroxyconiferaldehyde could. if operational in vivo, essentially prevent flux from caffecic acid to ferulic acid from occurring ( $\mathrm{Li}$ et al., 2000). These findings led to the suggestion that hydroxylation and $O$-methylation in monolignol biosynthesis occur at the level of the coenzyme A ester (for 3-O-methylation) or aldehyde (for 5-Omethylation). This was not the end of the story, however. In vivo labeling experiments in Magnolia kobus indicated that $S$ lignin can be derived from coniferyl alcohol. In these studies. side-chain labeled coniferyl alcohol was incorporated into $S$ lignin with complete retention of label, indicating direct incorporation (Matsui et al.. 1994: Chen et al.. 1999). Consistent with a pathway for hydroxylation and methylation at the alcohol level. COMT from alfalfa has a significantly higher aftinity for 5-hydroxyconiferyl alcohol than for caffeic acid (Parvathi et al., 2001). Finally, recombinant alfalfa COMT can also efficiently catalyze the 3-O-methylation of caffeyl aldehyde and alcohol, suggesting that COMT might also be involved in the 3-O-methylation of monolignol precursors at the aldehyde or alcohol levels (Parvathi et al.. 2001).
After many years of frustrated attempts to discover an enzyme that specifically hydroxylated 4coumarate to yield caffeate (coumarate 3-hydroxylase) and whose properties suggested an involvement in lignification (Bolwell and Butt, 1983), it has recently become clear that the enzyme that carries out this function acts not on free 4-coumarate but on a carboxylate ester that, in vitro, may be the ethyl, shikmate or quinate ester (Schoch et al., 2001; Franke et al., 2002; Franke et al., 2002). This enzyme is a cytochrome P450 (CYP98A3), and mutant Arabidopsis plants in which it is not expressed accumulate a novel lignin consisting primarily of $\mathrm{H}$ units, indicating that this enzyme is indeed involved in the 3-hydroxylation reaction of lignin biosynthesis (Franke et al., 2002). A major question now is whether other reactions in the monolignol pathway might also take place with previously unsuspected esterified substrates; this possibility is raised by the results of certain genetic modification experiments (see below).

The operation of the "shikimate ester shunt" drew attention to the possible role of the quinate/shikimate hydroxycinnamoyl transferase (HCT), an enzyme that had previously been related to biosynthesis of chlorogenic acid (3- $O$-caffeoyl quinate) (Ulbrich and Zenk, 1979), in monolignol biosynthesis. This enzyme is reversible, and would have to function in both forward and reverse directions in the scheme in Figure 1. The gene encoding this enzyme has recently been cloned from tobacco (Hoffmann et al., 2003).

Reduction of hydroxycinnamic acids to their corresponding alcohols is initiated by formation of coenzyme A thioesters that are reduced successively to the corresponding aldehydes by cinnamoyl $\mathrm{CoA}$ reductase(s) (CCR) and cinnamyl alcohol dehydrogenases(s) (CAD). Hydroxycinnamate: CoA ligases $(4 \mathrm{CL})$ have been characterized at the molecular level from many plant species. In general, these enzymes exhibit highest activity against coumaric, caffeic and ferulic acids, with little activity against cinnamic and sinapic acids (Ehlting et al., 1999). The apparent lack of activity of $4 \mathrm{CL}$ against sinapic acid in several plants calls into question the role of sinapate as a lignin precursor, consistent with the pathways proposed in Figure 1. A recent study that combined analysis of $4 \mathrm{CL}$ specificity with in vivo labeling with sinapate has confirmed that, in Arabidopsis and magnolia, sinapate is not an intermediate in $\mathrm{S}$ lignin biosynthesis (Yamauchi et al., 2003). However, in oleander and robinia. $4 \mathrm{CL}$ was active with sinapate and labeled sinapate was incorporated into lignin. Thus, $\mathrm{S}$ lignin biosynthesis in 
angiosperms can occur by multiple pathways that are species-specific.

Additional enzymes may catalyze the methylation reactions shown in Figure 1. For example, young alfalfa internodes contain an OMT (COMT II), with preference for caffeic acid compared to 5hydroxyferulic acid. This enzyme can be separated from the previously characterized COMT (COMT I) by anion exchange and hydrophobic interaction chromatography (Inoue et al., 2000). COMT II differs from COMT I in its native $\mathrm{Mr}$, pH optimum, and its very low $\mathrm{Km}$ for caffeic acid. COMT II may therefore be a true caffeic acid OMT (although the enzyme is also active with coenzyme A esters and some flavonoids), and may be involved in formation of ferulic acid in the earliest stages of lignification in young tissues. A similar "early" form of COMT has been described in wheat seedlings (Lam et al., 1996). Another interesting OMT potentially involved in lignification has been identified in loblolly pine ( $\mathrm{Li}$ et al., 1997). Called AEOMT (acids and esters OMT), this enzyme has approximately equal preference for caffeic acid and caffeoyl CoA. To date, a potential function for this enzyme in lignification has only been inferred from its in vitro biochemical activities.

\section{Regulatory genes for monolignol biosynthesis}

The concentrations of the inter- and extra-cellular proteins involved in monolignol biosynthesis and polymerization are controlled, in large part, by transcriptional events. Although the transcriptional control of monolignol biosynthetic genes in relation to vascular development is not well understood, several transcription factors have been shown to affect lignification. These have been identified by two distinct approaches: analysis of factors with binding affinity for cis-elements in the promoters of monolignol biosynthetic genes, and mutational analysis.

The Antirrhinum MYB transcription factors AmMYB308 and AmMYB330, when over-expressed in transgenic tobacco, repress lignin biosynthesis (Tamagnone et al., 1998). Expression of AmMYB 308 strongly reduced steady state transcript levels of $4 \mathrm{CL}$ and $\mathrm{CAD}$, with a smaller effect on cinnamate 4-hydroxylase $(\mathrm{C} 4 \mathrm{H})$ and no effect on phenylalanine ammonialyase (PAL) transcripts. In vitro, AmMYB308 was a weak transcriptional activator of the $4 \mathrm{CL}$ promoter, leading to the suggestion that the repressive effect of over-expression was due to competition for the natural MYB regulator of $4 \mathrm{CL}$ expression (Tamagnone et al., 1998). PAL expression is up-regulated by expression of a different MYB protein, AtMYM305, in tobacco (Urao et al., 1993). Many phenylpropanoid pathway genes contain binding sites for MYB family transcription factors in their promoters (Martin and Paz-Ares, 1997), and some $M Y B$ genes are highly expressed in stem tissue undergoing vascular differentiation (Martin and Paz-Ares, 1997). These observations suggest novel approaches for modification of lignin content and composition by altering expression of endogenous MYB transcription factors or by interfering with endogenous MYB protein function by expression of foreign $M Y B$ genes.

\section{Genomics approaches to lignin biosynthesis in Medicago truncatula}

Medicago truncatula (also known as barrel medic because of the shape of its seed pods) is a forage legume commonly grown in Australia. It originates from Mediterranean regions, and has recently been introduced as a warm season annual legume to the Gulf Coast States in the US. M. truncatula is very closely related to the world's major forage legume, alfalfa (Medicago sativa). However, whereas alfalfa has a complex genome consisting of four copies of each of its eight chromosomes and is an outcrossing plant, $M$. truncatula has a simple diploid genome and can be self-pollinated, facilitating genetic analysis.

$M$. truncatula has been chosen as a model species for genomic studies in view of its small genome. fast generation time and genetic transformation efficiency (Cook, 1999). Genes from M. truncatula share very high sequence identity to their counterparts from alfalfa, and also appear to be arranged in a similar order on the chromosomes, making $M$. truncatula an excellent model for understanding the molecular biology of alfalfa. We have utilized $M$. truncatula as a model species for a genomics-based approach to understanding monolignol biosynthesis. The rationale for using this species is two-fold. First, from a practical viewpoint, the other genomically tractable model dicot, Arabidopsis, is a small plant with a rosette habit that is less than optimal for studies on lignification in vegetative stem tissue. Secondly, lignin modification is an important trait in Medicago species in relation to its impact on forage digestibility.

The development of rapid expressed sequence tag (EST) and genomic sequencing technologies has al- 
lowed an unprecedented increase in our understanding of the complexity of gene families in plants. It is now possible, for several model and agronomically important plants. to view and analyze sequences of all gene family members, and compute their expression patterns in silico, by simple search and query commands with various Plant Gene Index databases, such as those available at the TIGR website (http://www.tigr.org/tdb/tgi.shtml) (Quackenbush et al.. 200()). The Medicago gene index at the National Center for Genome Resources (Bell et al., 2001) and the TIGR Medicago gene index, provide information on over 190.000 ESTs from M. truncatula, and a whole genome sequence for $M$. truncatula was recently announced (Trends in Plant Science 7, 101, 20(2). An important feature of the M. truncatula EST data is that nearly 40 different cDNA libraries, representing a range of tissues and biological conditions, have been sequenced, greatly facilitating in silico analysis of gene expression patterns.

\section{Comparative genomics of the lignin biosynthetic pathway}

Table I summarizes the apparent numbers of gene family members for various genes potentially involved in the biosynthesis of monolignols in Medicago truncatula. Arabidopsis, riee and maize. The numbers refer to tentative consensus secuences (TCs) that represent EST contigs derived from clustering of the EST seguences. Every TC annotated in the database as representing a specific gene product has been counted as such. Singletons (secquences that occur only once in the database and do not show overlap with other EST sequences) are also included in the analysis. With over 200.000 ESTs now sequenced in $M$. truncatula, the data in Table 1 probably represent a fairly accurate picture of gene family complexity.

Two important conclusions can be made from the data in Table 1. First. in all four species, many of the genes exist as large gene families. In the cases of $4 C L$, $C C R$, and $C A D$, these may have ten or more members. Second. the levels of complexity differ between the different species e.g. a single $4 C L$ gene in rice, 10 or more in Arabidopsis and $M$. truncutula. In spite of extensive EST sequencing. some genes that must exist have yet to be represented in the EST databases, such as $\mathrm{C} 4 \mathrm{H}$ in maize. This may be a problem of selectivity of sequenced libraries. low transcript abundance, or poor annotation.
As a note of caution, the EST counting approach annotates genes based solely on sequence similarity, and does not infer functional identification of a particular gene product. Thus, some of the genes annotated as encoding a particular enzyme may in fact encode related enzymes with different but related functions. Only in vitro expression and assay of the individual forms can distinguish between these possibilities. Furthermore, there is emerging evidence to indicate that some enzymes of natural product biosynthesis, including "monolignol" enzymes such as COMT, have relatively promiscuous substrate specificities (Maury et al. 1999), and could theoretically be involved in multiple pathways. Reverse genetic approaches will be required to resolve such issues.

To date, most transgenic approaches to lignin modification have not taken into account the potential complexity of the gene families being targeted. It is thus possible that closely related genes in addition to the target gene have been down-regulated, or less related genes with the same function have escaped down-regulation. Definitive information as to why many of the gene families in Table 1 are so complex, and what the functions of the specific gene family members are, will require specific down-regulation of the individual gene forms. This has been problematical in the past owing to the often very high DNA sequence conservation between family members. Because of this, use of antisense or gene silencing with large sequence fragments would result in down-regulation of several or maybe all the genes. Recent advances in plant gene silencing technology based on an understanding of RNA-interference (RNAi) (Wesley et al., 2001 ) should now facilitate the molecular dissection of the functions of individual members of the monolignol pathway gene families, with the proviso that overlapping specificities and gene redundancy might complicate the picture. This information may allow for more precise engineering of lignin and lignan biosynthesis. It is intriguing to consider the possibility that some gene family members may be specific for lignin biosynthesis, with others involved in parallel reactions in lignan formation.

\section{Lignin pathway gene complexity in Medicago truncatula}

Phenylalanine ammonia-lyase (PAL). PAL catalyzes the entry point reaction into phenylpropanoid biosynthesis and as such is expected to be an early regu- 
Table 1. Gene family members involved in the biosynthesis of monolignols in Medicago) trunc atula

\begin{tabular}{|c|c|c|c|c|c|c|}
\hline \multirow[b]{2}{*}{ Enzyme name } & \multicolumn{6}{|c|}{ Tentative consensuses (TCs) or singletons in TIGR databases } \\
\hline & M. truncatula & Soybean & Tomato & Arabidopsis & Rice & Maizc \\
\hline \multicolumn{7}{|c|}{ Phenylalanine ammonia-lyase (PAL) } \\
\hline & TC60344 & TC120178 & TC 98559 & TC149606 & TC100267 & TC 155705 \\
\hline & TC64086 & TC120179 & TC98560 & TC149607 & TC 104767 & $\mathrm{TC} 1592.36$ \\
\hline & TC65562 & TC120180 & TC98561 & TC149868 & TC 104764 & TC 1592.37 \\
\hline & TC68095 & $\mathrm{TCl} 26818$ & TC 98669 & TC149869 & TC 10476.5 & TC1.592.38 \\
\hline & TC68096 & & TC105208 & TC158072 & TC104766 & TC1592.39 \\
\hline & TC68097 & & TC107313 & T4.5207 & $\mathrm{TC} 104768$ & $\mathrm{TCl} 160541$ \\
\hline & TC68378 & & TC110806 & & AW 155403 & $\mathrm{TCl} 60542$ \\
\hline & TC68379 & & TC111296 & & AW 155576 & $\mathrm{TCl} 160543$ \\
\hline & TC68380 & & AW 035278 & & D 49142 & \\
\hline & & & B1203204 & & $\mathrm{AU}(068510$ & \\
\hline & & & BG73.5223 & & $\mathrm{BE} 040736$ & \\
\hline \multicolumn{7}{|c|}{ Cinnamate 4-hydroxylase $(\mathrm{C} 4 \mathrm{H})$} \\
\hline & TC68098 & TC132363 & TC110509 & TC150023 & $\mathrm{AU} 0580.37$ & \\
\hline & TC68099 & $\mathrm{TC} 1.32364$ & & & & \\
\hline \multicolumn{7}{|c|}{ 4-Coumarate:coenzyme A ligase (4CL) } \\
\hline & TC60026 & TC120553 & TC98405 & TC1509.30) & TC 97.362 & TC151583 \\
\hline & TC65453 & TC133962 & TC 99481 & $\mathrm{TC} 150931$ & $\mathrm{TC} 99641$ & TC151664 \\
\hline & TC65681 & TC120554 & TC100408 & TC151848 & TC100881 & $\mathrm{TC} 161152$ \\
\hline & TC66680 & TC120557 & $\mathrm{TC} 101174$ & TC15.3791 & $\mathrm{TC} 103416$ & TC16.3817 \\
\hline & TC69081 & TC124508 & TC 103426 & TC163721 & TC 105867 & $\mathrm{TCl} 167404$ \\
\hline & TC69772 & TC125645 & TC104412 & TC167.5.34 & $\mathrm{TC} 106460$ & \\
\hline & TC70400 & $\mathrm{TC} 128381$ & $\mathrm{TC} 106474$ & NP281186 & TC1065.31 & \\
\hline & TC71682 & $\mathrm{TC} 131261$ & TC106804 & & $\mathrm{TC} 108475$ & \\
\hline & TC72216 & TC133929 & TC112965 & & TC108664 & \\
\hline & TC75402 & $\mathrm{TC} 136358$ & AW0.31.547 & & TC110024 & \\
\hline & & TC136890 & AW 034240 & & NP0024)7 & \\
\hline & & & AW039905 & & NP3026.38 & \\
\hline & & & AW616655 & & NP409757 & \\
\hline & & & AW625022 & & AW 155336 & \\
\hline & & & BE449653 & & & \\
\hline \multicolumn{7}{|c|}{ Hydroxycinnamoyl transferase (HCT) } \\
\hline & TC59732 & TC133435 & TC100265 & TC156505 & TC. $1045(0) 3$ & TC 1506.57 \\
\hline & & TC13.3436 & TC100669 & $\mathrm{TC} 161029$ & TC1052.32 & TC15.3392 \\
\hline & & TC133437 & & $\mathrm{TCl} 61691$ & $\mathrm{TC} 107940$ & \\
\hline & & & & & NP451642 & \\
\hline \multicolumn{7}{|c|}{ Coumarate 3-hydroxylase $(\mathrm{C} 3 \mathrm{H})$} \\
\hline & TC60163 & $\mathrm{TC} 133516$ & TC102069 & TC149793 & & \\
\hline & & & TC107838 & & & \\
\hline & & & TC108065 & & & \\
\hline \multicolumn{7}{|c|}{ Caffeic acid $O$-methyl-transferase (COMT) } \\
\hline & TC51781 & TC133647 & TC101479 & $\mathrm{TC} 152369$ & ТC972()9 & $\mathrm{TC} 149270$ \\
\hline & TC59577 & TC13.3648 & TC101929 & TC15.5499 & & $\mathrm{TCl} 49271$ \\
\hline & TC59579 & & TC109048 & TC156743 & & TC151662 \\
\hline & TC59990 & & & TC162925 & & \\
\hline & TC67955 & & & TC162926 & & \\
\hline & TC67956 & & & NP2.369.39 & & \\
\hline & TC69180 & & & & & \\
\hline & TC74636 & & & & & \\
\hline
\end{tabular}


Table I. Continued

\begin{tabular}{|c|c|c|c|c|c|c|}
\hline \multirow[b]{2}{*}{ Finzyme name } & \multicolumn{6}{|c|}{ Tentative consensuses (TCs) or singletons in TIGR databases } \\
\hline & M. trumcitula & Soybean & Tomato & Arabidopsis & Rice & Maize \\
\hline \multicolumn{7}{|c|}{ Caffeoyl coenzyme A O-methyl-transferase (CCoAOMT) } \\
\hline & TC619()3 & TC12.3959 & TC98418 & $\mathrm{TC} 149810$ & TC98369 & TC159998 \\
\hline & TC(619)4 & $\mathrm{TC} 126458$ & TC987.38 & TC153568 & TC104956 & TC160367 \\
\hline & TC68.37I & $\mathrm{TC} 127146$ & TC987.39 & TC153569 & NP001843 & TC1521.58 \\
\hline & TC 68997 & $\mathrm{TC} 132670$ & $\mathrm{TC} 10(0264$ & TC170490 & & \\
\hline & & $\mathrm{TC} 132671$ & $\mathrm{TCl} 02387$ & AA 394533 & & \\
\hline & & $\mathrm{TC} 132673$ & AI776146 & & & \\
\hline & & TC132674 & AW219626 & & & \\
\hline & & TC13274.5 & & & & \\
\hline & & $\mathrm{TC} 1.32746$ & & & & \\
\hline & & $\mathrm{TC} 132748$ & & & & \\
\hline \multicolumn{7}{|c|}{ Ferulate 5-hydroxylase ( $\mathrm{F} 5 \mathrm{H}$ ) } \\
\hline & TC6.52.37 & $\mathrm{TC} 122880$ & TCl 102880 & TC150466 & TC108119 & \\
\hline & TC68915 & & $\mathrm{TC} 106767$ & NO281450 & & \\
\hline \multicolumn{7}{|c|}{ Cinnamoyl coenzyme A reductase (CCR) } \\
\hline & TC.5978.5 & $\mathrm{TC} 121013$ & $\mathrm{TCl} 100442$ & $\mathrm{TC} 154177$ & TC97148 & TC149677 \\
\hline & TC70266 & $\mathrm{TC} 121015$ & $\mathrm{TC} 102105$ & $\mathrm{TC} 155063$ & TC97149 & TC149679 \\
\hline & TC68.3.30 & TC124904 & TC 107062 & TC161141 & TC97789 & TC150846 \\
\hline & TC60893 & $\mathrm{TC} 128675$ & TC107476 & TC161670 & TC98316 & TC152275 \\
\hline & TC60894 & TC129395 & TC109165 & $\mathrm{TC} 166923$ & TC99014 & TC154542 \\
\hline & TC686()4 & $\mathrm{TC} 132311$ & & TC157466 & TC100822 & TC157145 \\
\hline & & $\mathrm{TC} 132313$ & & $\mathrm{TC} 161648$ & TC100974 & TC166720 \\
\hline & & TC1.34196 & & TC161649 & TC101444 & NP003454 \\
\hline & & $\mathrm{TC} 1.34197$ & & $\mathrm{TC} 167535$ & TC106057 & NP003455 \\
\hline & & TC1.39658 & & TC16754I & TC107202 & \\
\hline & & TC1.39724 & & BE 522400 & TC107430 & \\
\hline & & & & & TC107510 & \\
\hline & & & & & AU064260 & \\
\hline & & & & & AW 155595 & \\
\hline & & & & & C73909 & \\
\hline & & & & & BI306691 & \\
\hline & & & & & AU1741.35 & \\
\hline & & & & & D 481.35 & \\
\hline \multicolumn{7}{|c|}{ Cinnamyl alcohol dehydrogenase (CAD) } \\
\hline & TC61.379 & $\mathrm{TC} 125122$ & ТC 99774 & $\mathrm{TC} 150052$ & TC105400 & TCI60262 \\
\hline & TC 61.380 & TC. 1.32545 & $\mathrm{TC} 100576$ & $\mathrm{TC} 150367$ & TC108577 & TC162614 \\
\hline & TC62212 & TC1.32547 & TCI02029 & TC150431 & TC105215 & TC155193 \\
\hline & TC6221.3 & $\mathrm{TC} 1.32548$ & TC105106 & TC154254 & TC106887 & TC150069 \\
\hline & $\mathrm{TC}(67973$ & $\mathrm{TC} 1.32604$ & TC106936 & TC161262 & TC107624 & TC157053 \\
\hline & TC68444 & TC1.32605 & AW037980 & TC161322 & TC10005. & \\
\hline & TC72882 & TC132606 & & TC168050 & TC107701 & \\
\hline & AW6968.39 & TC1.33407 & & TC159031 & TC112544 & \\
\hline & AW559294 & & & TC165297 & ТC 99454 & \\
\hline & & & & NP040876 & & \\
\hline & & & & NP040879 & & \\
\hline & & & & NP307424 & & \\
\hline
\end{tabular}


latory control point for monolignol biosynthesis. The in silico expression pattern of the nine $M$. truncatula $P A L$ or $P A L$-like genes in different tissues and in response to different biotic and abiotic stimuli is shown in Figure 2. Only three of the nine TCs (68378, 68095 and 60334) correspond to genes that are expressed in stems and are therefore candidates for involvement in stem lignification. There is no relation between sequence relatedness and expression pattern; for example, TC 68095 and 60334 are the most strongly expressed in stem, but do not cluster together based on sequence.

In contrast to the complex Medicago PAL gene family, tobacco contains two families of $P A L$ genes (PALI and PAL2), each family comprising two very closely related members. Protein gel blot analysis showed that PAL1 is localized in both soluble and microsomal fractions from tobacco stems and cell cultures, whereas PAL2 is only found in the soluble fraction (Rasmussen and Dixon, 1999). This suggests that PAL1 is the form of PAL involved in direct coupling to the membrane associated $\mathrm{C} 4 \mathrm{H}$ (see below), and this has recently been confirmed by various in vivo immunocytochemical and immunofluorescence approaches coupled with laser confocal microscopy (L. Achnine, E. Blancaflor, S. Rasmussen and R.A. Dixon, unpublished results). It is possible that different forms of PAL with different sub-cellular localization may be associated differentially with $\mathrm{S}$ and $\mathrm{G}$ lignin and lignan biosynthesis, consistent with over-expression of a specific (transgene) PAL form affecting S/G ratio in transgenic tobacco (Sewalt et al., 1997). Such a channeled model for monolignol biosynthesis would allow for the fine control over production of $\mathrm{G}$ and $\mathrm{S}$ units that is required for the observed temporal and spatial regulation of lignin composition. Such a model does, however, still await definitive proof.

The data in Figures 2-6 show that many of the $P A L$ and downstream monlignol pathway genes are modulated in response to abiotic and biotic stimuli, or expressed in tissue where lignification may not occur. This highlights the importance of the monolignol pathway for the synthesis of a range of end products with various functions including microbial and insect defense, establishment of interactions with pathogenic microorganisms, growth regulation, etc (Binns et al., 1987; Delay et al., 1994; Barber et al., 2000).

Cytochrome P450 enzymes $(\mathrm{C} 4 \mathrm{H}, \quad$ "C $3 \mathrm{H}$ " and " $F 5 H$ "). In contrast to PAL, the cytochrome P450 enzymes involved in monolignol biosynthesis $(\mathrm{C} 4 \mathrm{H}$,
"C $3 \mathrm{H}$ " and "F5H") each only appear to be encoded by one gene or a pair of genes in $M$. truncatula. of which one appears to be predominantly expressed in stems (Figure 3). Down-regulation of "C $3 \mathrm{H}^{\prime \prime}$ and "F5H", and over-expression of "F5H", all have major impacts on lignin content and/or composition in other plants such as tobaceo and Arabidopsis (Meyer et al., 1998; Franke et al., 20()(); Franke et al., 20()2). These effects are quantitatively greater than the effects of altering expression of any of the other enzymes in the pathway downstream of $\mathrm{C} 4 \mathrm{H}$, consistent with differences in the numbers of potential targets for down-regulation between each $\mathrm{P} 450$ and non-P450 enzyme in the pathway.

4-Coumarate: CoA ligase. M. truncatula appears 10 express at least 10 TCs that are annotated as encoding 4CL (Figure 4A, B). These may not all encode true 4CL enzymes acting on hydroxycinnamic acids, as 4CL-like enzymes are also known that utilize a similar reaction mechanism involving activation of an acidic function by formation of an acyl adenylate (Cukovic et al., 2001; Ehlting et al., 2001). None of the $M$. truncatula $4 \mathrm{CL}$ TCs has yet been functionally characterized, although distinct isoforms of $4 \mathrm{CL}$ have been enzymatically characterized in other species (Knobloch and Hahlbrock, 1975; Vincent and Nicholson, 1987; Lee and Douglas, 1996). Their biochemical properties indicate some degree of preference for the variously substituted hydroxycinnamic acids, but do not necessarily suggest specific cellular functions, e.g. in lignification.

() the $10 \mathrm{M}$. truncatula 4CL ESTs, four are expressed in stem tissue, but none particularly highly when compared to the level of expression of TC69081 in yeast elicited cell cultures. Figure $4 \mathrm{~A}$ shows a dendrogram of the $M$. tuncatula $4 \mathrm{CL}$ TCs summarizing sequence comparisons with other plant 4CLs in the GenBank database. Genes that have been targeted for lignin modification in transgenic plants are shown in bold. The contradictory eflects on lignification of transgenically down-regulating $4 \mathrm{CL}$ in different. or even the same, species (Kajita el al., 1996; Lee et al., 1997; Hu et al., 1999), may well be a result of the complexity of the $4 C L$ gene family. None of the studies to date has used gene specific probes or arrays to determine the exact pattern of transcript down-regulation oblained for the different gene family members.

Hydroxycinnamoyl transferase (HCT). To date, only a single TC corresponding 10 HCT has emerged from 


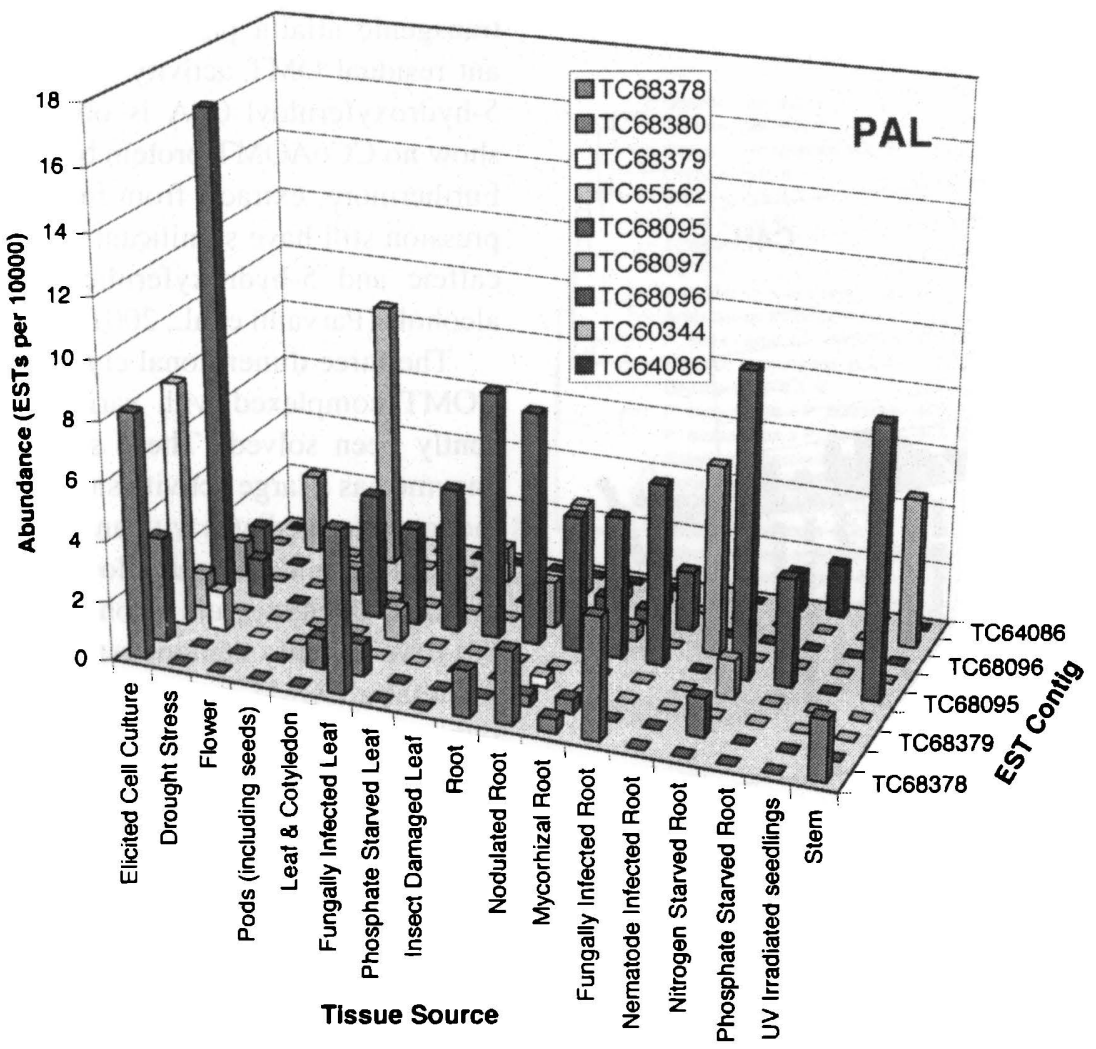

Figure 2. In silico expression analysis of PAL genes in $M$. truncurula. This species currently has close to 200,000 reported EST sequences, from nearly 40 different cDNA libraries, deposited in publicly available databases. EST sequences can be clustered into tentative consensus (TC) sequences, representing transcripts originating from one specific gene. In the case of PAL, nine such TCs currently exist. It is possible to query the database to determine the number of times an EST corresponding to a particular TC has been sequenced in a particular library or group of libraries. This number can then be expressed as a function of the total number of ESTs sequenced in that library(s) to give an approximate value for the expression level of the gene represented by that TC. See Dixon et al. (2002) for further details of this approach.

the M. truncatula EST sequencing projects. This appears to be expressed in all libraries examined to date, with the exception of UV-induced seedlings (Figure 5), and is therefore probably involved in multiple pathways involving hydroxycinnamate esters.

O-Methyltransferases. Figure 6 shows expression patterns of the $M$. truncatula caffeic acid $O$ methyltransferase genes. There are seven COMT-like TCs in M. truncatula, three of which are expressed in stems and therefore potentially involved in lignification in that organ (Figure 6). Interestingly, TC59577, the ortholog of the alfalfa COMT gene that has been shown, by transgenic down-regulation, to be essential for S lignin biosynthesis (Guo et al., 2000), is not the most highly expressed COMT gene in stem tissue. TC67955 is expressed at approximately 3.5 times the level of TC59577 in stem, and is also very strongly represented in leaf and flower cDNA librar- ies (Figure 6). TC67955 is most closely related at the DNA sequence level to the AEOMT (acids/esters OMT) from Loblolly pine, an enzyme reported to be active against caffeic and 5-hydroxyferulic acids and their corresponding coenzyme A esters ( $\mathrm{Li}$ et al., 1997). However, TC67955, when expressed in either yeast or $E$. coli, appears to have no activity against caffeic acid or caffeoyl CoA, and preliminary results suggest no lignin phenotype on down-regulation or over-expression of the AEOMT-like gene in Medicago (P. Kota and R.A. Dixon, unpublished results). The existence of a novel $O$-methyltransferase gene(s) involved in monolignol biosynthesis in Medicago is predicted from the fact that strong down-regulation of both COMT and CCOAOMT in transgenic alfalfa is not additive and does not result in a strong reduction in lignin quantity (Inoue et al., 2000). Analysis of OMT substrate preferences in crude extracts from lignifying stems from wild-type and OMT down-regulated 
A

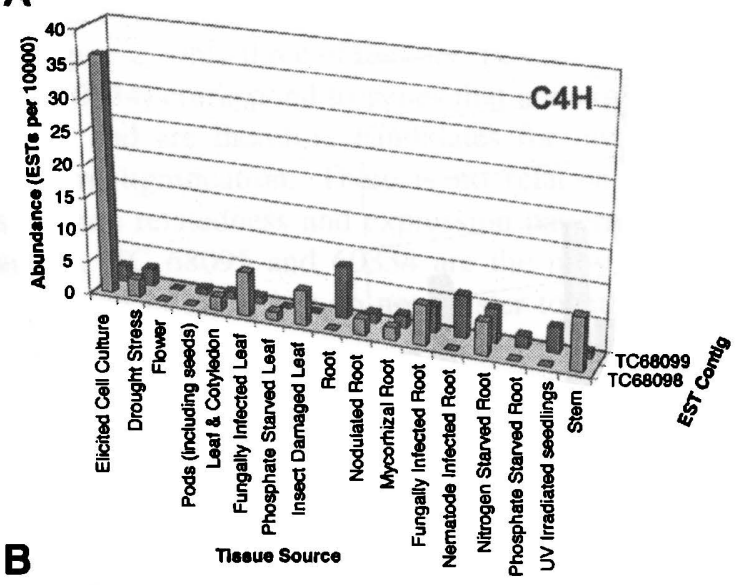

B
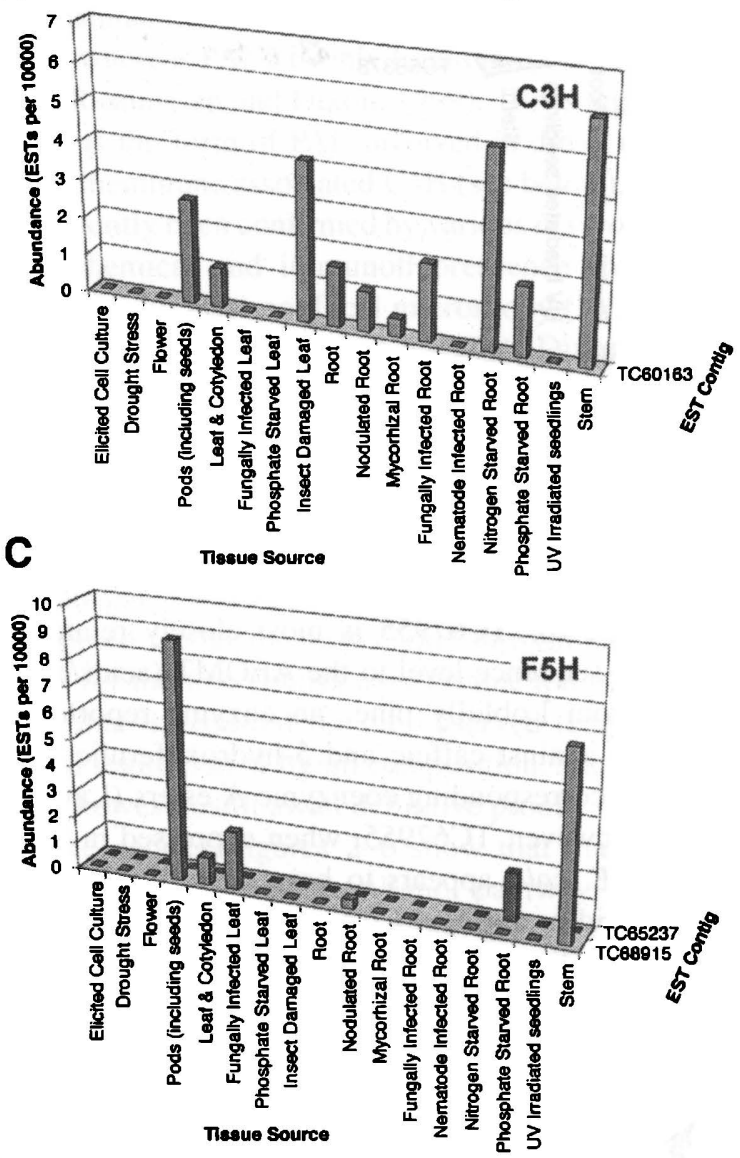

Figure 3. In silico expression analysis of cytochrome P450 genes encoding cinnamate 4-hydroxylase, "coumarate 3-hydroxylase" and "ferulate 5-hydroxylase" in M. truncatula. See legend to Figure 1 for explanation. transgenic alfalfa plants has indicated that significant residual OMT activity against caffeoyl CoA and 5 -hydroxyferuloyl $\mathrm{CoA}$ is observed in extracts that show no CCoAOMT protein by western blot analysis. Furthermore, extracts from lines with no COMT expression still have significant residual activity against caffeic and 5-hydroxyferulic acids, aldehydes and alcohols (Parvathi et al., 2001).

The three dimensional crystal structures of alfalfa COMT complexed with various substrates have recently been solved. These studies indicate that the enzyme has a large activite site cavity that can accommodate intermediates with and without the 5-hydroxyl substituent, and that can allow for correct positioning of acids, aldehydes and alcohols (Zubieta et al., 2002). We have recently demonstrated that the best substrate for alfalfa COMT is not a monolignol precursor but rather the vanillin precursor protocatechuic aldehyde, related to caffeyl aldehyde by the shortening of the side chain by two carbons (P. Kota and R.A. Dixon, unpublished results). The physiological significance of this observation is not clear, but the finding highlights the danger in assigning in vivo function to an enzyme based solely on in vitro substrate preference.

$M$. truncatula contains four TCs annotated as encoding CCoAOMT. The tissue-specific expression patterns of these genes have been summarized elsewhere (Dixon et al., 2002). Two of these genes are expressed in stems. Similar complexity in CCoAOMT expression has been reported in tobacco, which contains a number of COMT and CCOAOMT isoforms with different substrate specificities and expression patterns (Maury et al., 1999).

Cinnamoyl CoA reductase (CCR) and cinnamyl alcohol dehydrogenase (CAD). Both CCR and CAD are members of gene families in $M$. truncatula. Of the six CCR TCs, two have so far been functionally expressed and shown to encode proteins active in the reduction of all potential CoA esters shown in Figure 1, although one form has a strong preference for feruloyl CoA (Q. Ma and R.A. Dixon, unpublished results). Of the seven apparent CAD TCs in $M$. truncatula, four are expressed in stems, and, as in the case of $4 \mathrm{CL}$, the CAD form that appears to be most highly expressed in stem is also very strongly expressed in elicited cell cultures. To date, none of the $M$. truncatula CAD TCs has been functionally characterized. It is not therefore known whether $M$. truncatula contains a specific form of CAD that is preferentially involved in the reduc- 
A
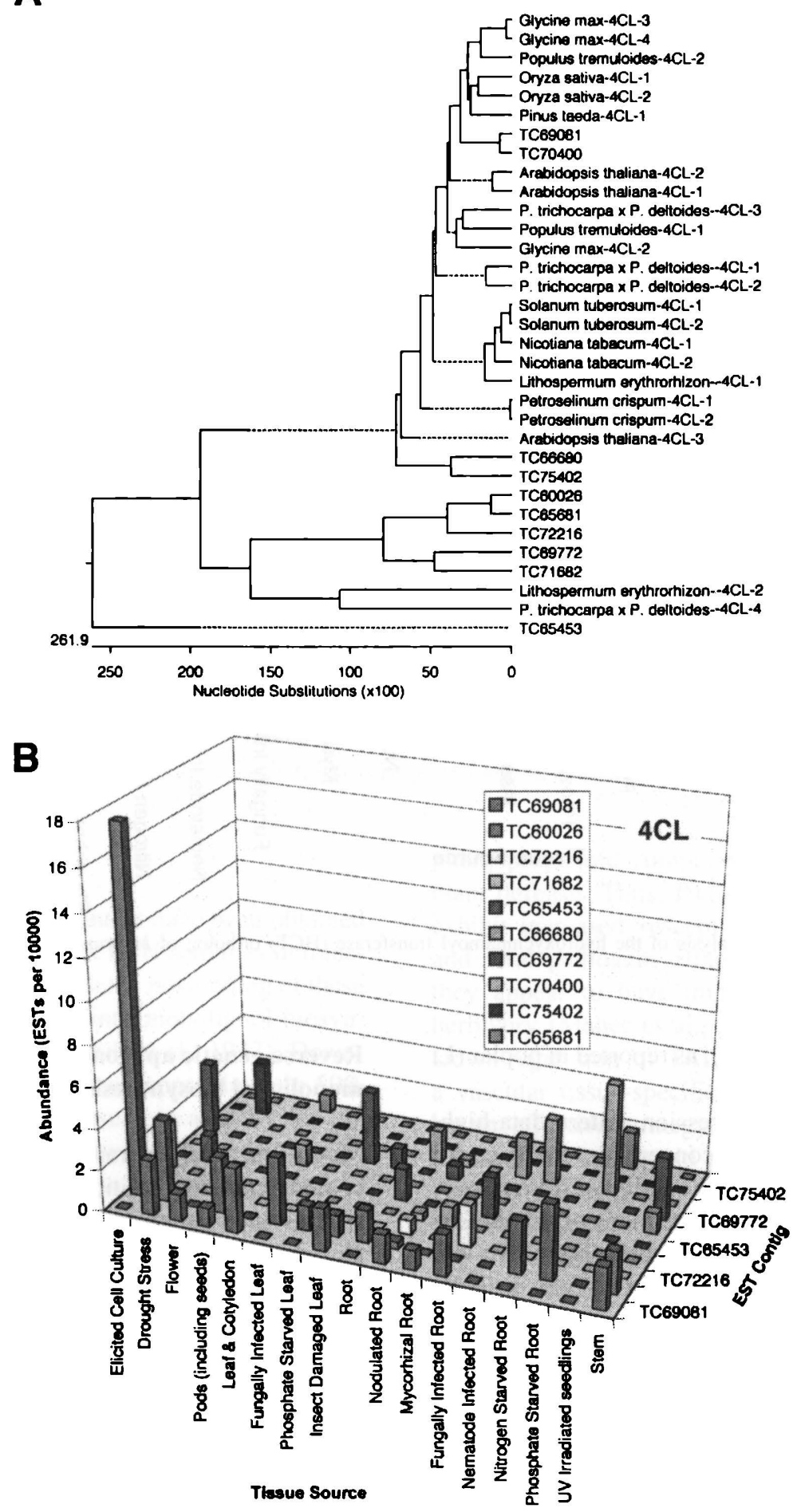

Figure 4. $4 C L$ genes in $M$. truncatula. (A) Dendrogram showing relatedness among $M$. truncatula $4 C L$ genes (based on TCs) and other known $4 \mathrm{CL}$ sequences. Sequences in bold represent genes that have been transgenically down-regulated to modify lignin content/composition. (B) In silico expression analysis; see legend to Figure 1 for explanation. 


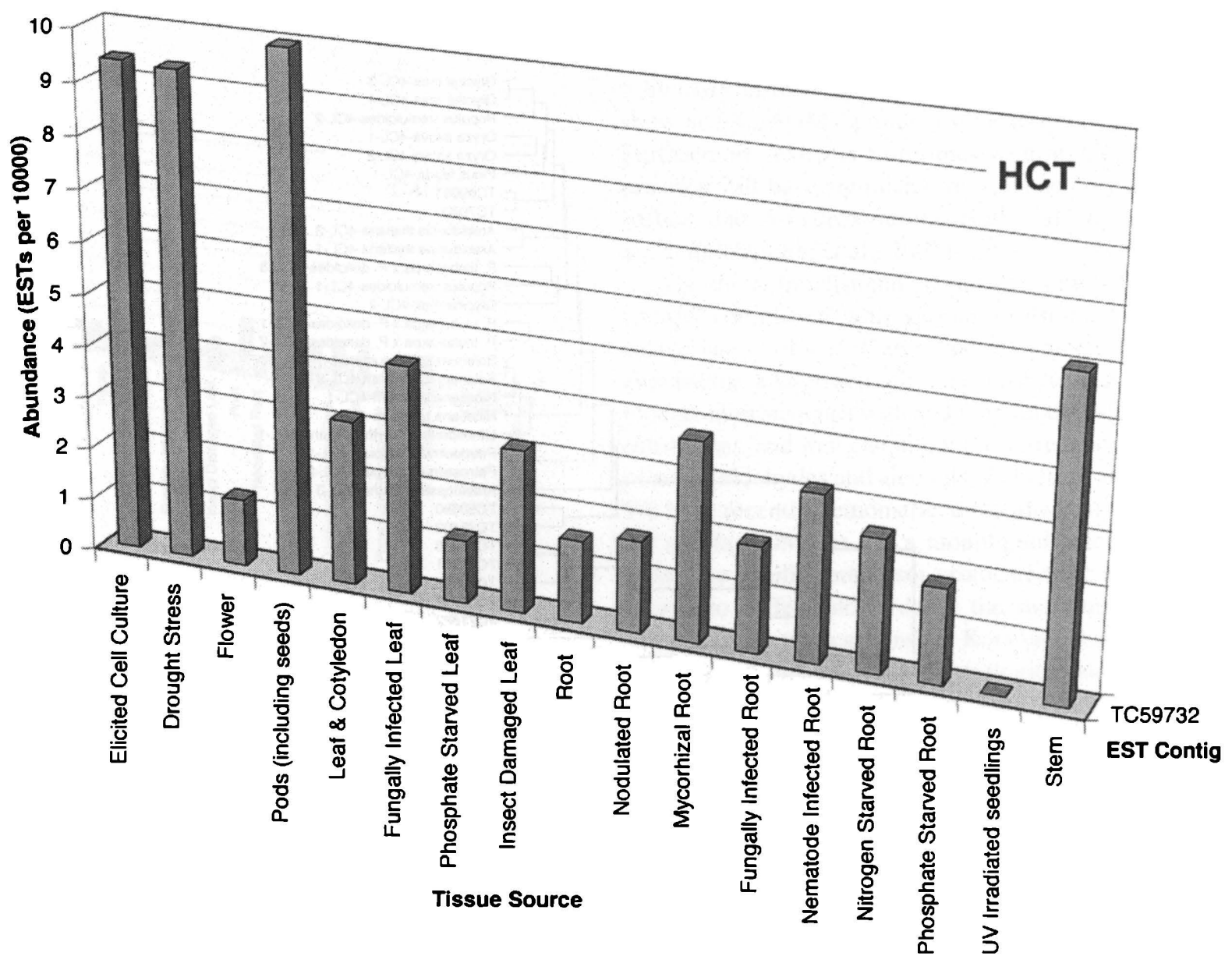

Figure 5. In silico expression analysis of the hydroxycinnamoyl transferase (HCT) ortholog of $M$. truncatula. See legend to Figure 1 for explanation.

tion of sinapaldehyde (SAD), as reported in poplar ( $\mathrm{Li}$ et al., 2001).

The above in silico expression pattern data highlight two important points concerning strategies for genetic modification of lignin and lignans. First, only by knowing the sequence relatedness of all the expressed gene family members in the target plant will it be possible to predict the extent to which downregulation of a particular enzymatic target will be complete. Second, many of the enzymes of lignin/lignan biosynthesis are expressed in a range of tissues, and in some of these their function may not necessarily be in lignification or lignan formation. Therefore, it may be advantageous to avoid constitutive down-regulation.

\section{Reverse genetic approaches to understanding monolignol biosynthesis}

Most of the work on transgenic manipulation of lignin content and composition has been done in model species such as tobacco, Arabidopsis and tree species such as poplar and Eucalyptus. Although the biosynthetic pathways to the monolignols, and the mechanisms of monolignol polymerization, are most likely conserved among plant species, there are clearly species-specific differences in the fine regulation of these processes. These basic similarities and specific differences are apparent on reviewing the now quite large body of literature describing transgenic modifications to the monolignol pathway but, unfortunately, there is as yet no analysis of the impact of sequential down-regulation of each step in the monolignol pathway in a single species. 


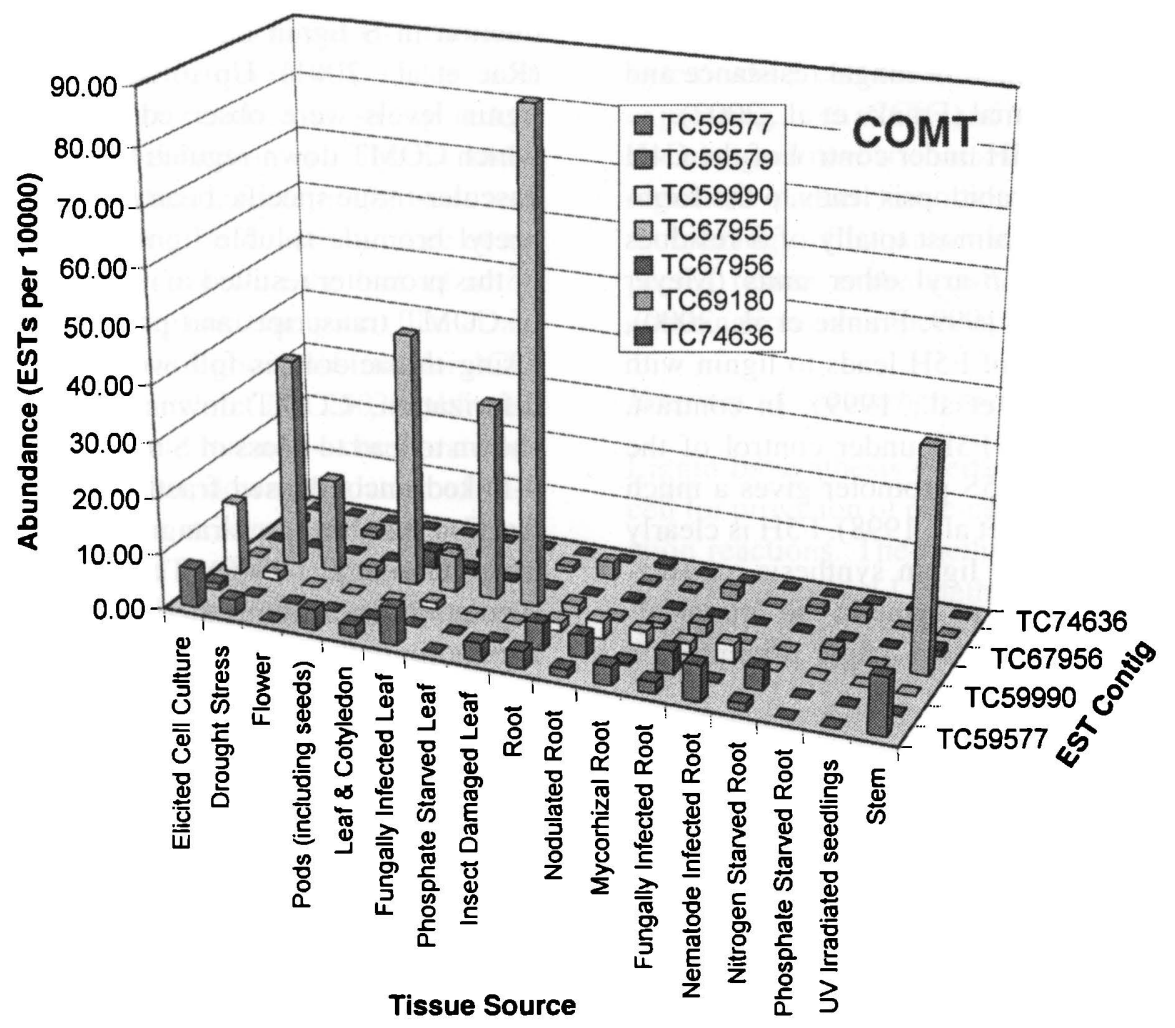

Figure 6. In silico expression analysis of COMT-like genes in M. truncatula. See legend to Figure 1 for explanation.

\section{$P A L$ and $C 4 H$}

Large reductions in lignin content have been obtained by down-regulation of PAL or $\mathrm{C} 4 \mathrm{H}$ activities in transgenic tobacco, consistent with the positioning of these enzymes at the entry point into monolignol biosynthesis (Bate et al., 1994; Sewalt et al., 1997). Downregulation of PAL leading to an approximately 50\% reduction in Klason lignin results in a near doubling of S/G ratio. In contrast, down- regulation of $\mathrm{C} 4 \mathrm{H}$ leading to a similar decrease in lignin content results in greatly reduced $S / G$ ratio, tending towards complete elimination of S units (Sewalt et al., 1997). This is quantitatively similar to the loss of S lignin observed following down-regulation of COMT (Atanassova et al., 1995; Van Doorsselaere et al., 1995) or F5H (Chapple et al., 1992) but none of the other enzymes of monolignol biosynthesis. The reason(s) for the opposite effects of down-regulation of PAL and $\mathrm{C} 4 \mathrm{H}$ on lignin composition have yet to be determined.

Constitutive down-regulation of $\mathrm{PAL}$ or $\mathrm{C} 4 \mathrm{H}$, although an effective approach for reducing lignin content, is unlikely to find practical application. This is because of the pleiotropic effects on levels of other phenylpropanoid compounds that are important for plant defense. Thus, PAL-suppressed tobacco plants exhibit increased susceptibility to fungal, bacterial, and viral pathogens although, perhaps surprisingly, they appear to have improved resistance to insect herbivory (Maher et al., 1994; Felton et al., 1999). Down-regulation of PAL or $\mathrm{C} 4 \mathrm{H}$ under control of a vascular tissue-specific promoter might, however, be an effective strategy, assuming that other nonlignin phenylpropanoid compounds produced in the vascular elements are not required for plant health or development.

\section{$\mathrm{C} 3 \mathrm{H}$ and $\mathrm{F} 5 \mathrm{H}$}

The ref8 mutant of Arabidopsis lacks expression of CYP98A3, the enzyme involved in the 3hydroxylation of hydroxycinnamate esters. Although initially identified based on the lack of sinapate esters in the leaves, this mutant has an unusual lignin built primarily from 4-coumaryl alcohol, consistent with the block in 3-hydroxylation. However, like PAL down-regulated plants (Felton et al., 1999), the mutation causes pleiotropic effects due to reduction 
in important non-lignin phenylpropanoid compounds, and is consequently impaired in fungal resistance and is developmentally abnormal (Franke et al., 2002).

Over-expression of $\mathrm{F} 5 \mathrm{H}$ under control of the $\mathrm{C} 4 \mathrm{H}$ promoter in transgenic Arabidopsis leads to the formation of lignin composed almost totally of $S$ residues linked predominantly in $\beta$-aryl ether units (Meyer et al., 1998; Marita et al., 1999; Franke et al., 2000), whereas down-regulation of $\mathrm{F5H}$ leads to lignin with very few S units (Marita et al., 1999). In contrast, constitutive expression of $\mathrm{F} 5 \mathrm{H}$ under control of the cauliflower mosaic virus $35 \mathrm{~S}$ promoter gives a much weaker phenotype (Meyer et al., 1998). F5H is clearly a major control point in $\mathrm{S}$ lignin synthesis, consistent with the position of the enzyme in the "classical" pathway and its revised position acting primarily on 5-hydroxyconiferaldehyde.

\section{OMTs}

There have been several reports on the effects of downregulation of COMT activity on lignin content and composition in transgenic plants, and the brown midrib3 mutation in maize results from the insertion of a retrotransposon in the COMT gene (Vignols et al., 1995) with the phenotype being reproduced by targeted down-regulation of COMT (Piquemal et al., 2002). Although the first study on COMT downregulation in transgenic tobacco plants reported reductions in lignin content with no significant changes in lignin composition ( $\mathrm{Ni}$ et al., 1994), it has since been consistently observed that strong down-regulation of COMT in species as diverse as tobacco and poplar results in a drastically reduced S/G ratio due primarily to inhibition of S lignin biosynthesis (Atanassova et al., 1995; Van Doorsselaere et al., 1995). Furthermore 5-hydroxyguaiacyl residues accumulate in the lignin of COMT down-regulated plants (Atanassova et al., 1995; Van Doorsselaere et al., 1995). Although reduction in $\mathrm{S}$ units is the major feature of lignin in COMT down-regulated plants, reduction of COMT activity in the xylem of quaking aspen (poplar) also results in a red-brown coloration resulting from high amounts of coniferaldehyde (Tsai et al., 1998). Furthermore, strong down-regulation of COMT in transgenic poplar resulted in a significant $(17 \%)$ decrease in overall lignin level in 6-month old trees (Jouanin et al., 2000).

$35 \mathrm{~S}$ promoter-driven antisense reduction of COMT to less than $5 \%$ of wild-type values in the tropical pasture legume Stylosanthes humilis resulted in no apparent reduction in lignin levels but in a strong re- duction in $\mathrm{S}$ lignin based on histochemical analysis (Rac et al., 2001). Up to 30\% decreases in Klason lignin levels were observed in transgenic alfalfa in which COMT down-regulation was targeted using the vascular-tissue specific bean PAL2 promoter, although acetyl bromide soluble lignin was not reduced. Use of this promoter resulted in near total down-regulation of C(OMT transcripts and protein (Guo et al.. 20(0)). Using thioacidolysis followed by Raney nickel desulfurization, COMT down-regulation in alfalfa was shown to lead to a loss of $\mathrm{S}$ residues in both the $\beta-O$ 4-linked uncondensed fraction and in the condensed fraction resolved as a range of differently linked dimers (Guo et al., 2000). The effect of C()MT downregulation on $\mathrm{S}$ lignin therefore likely reflects a true metabolic reduction in $S$ units, rather than a change in lignin composition resulting in appearance of more $S$ units in the non-condensed fraction of the polymer. Loss of S-units was accompanied by appearance of thioacidolysis-determined 5-hydroxyguatiacyl residues in the lignin, and the presence of these residues, and their linkage to yield novel lignin benzodioxane units. has been confirmed by the use of 2 -dimensional NMR techniques (Marita et al. 20()2).

In tobacco, down-regulation of CCoA()MT leads to a corresponding decrease in Klason lignin levels. associated with a reduction in both $S$ and $G$ lignin monomers (Zhong et al., 1998). This linding. when considered in relation to the strong reduction of $S$ lignin in COMT down-regulated plants, has been interpreted as indicating that $\mathrm{CCOAO}$ MT is involved in 3-O-methylation during the formation of both $\mathrm{G}$ and $\mathrm{S}$ monolignols, whereas $\mathrm{COMT}$ functions primarily in 5-O-methylation during $\mathrm{S}$ lignin biosynthesis. However, similar comparisons of effects of C()MT and $\mathrm{CCoA(OMT}$ down-regulation in alfalla suggest that this is not necessarily true in all plants. Near elimination of $\mathrm{CCOAOMT}$ activity reduced $\mathrm{G}$ lignin by up to $50 \%$ in some alfalla lines, but with no effect on $S$ lignin (Guo et al., 200()).

\section{$4 C L$}

The results of down-regulation of $4 \mathrm{CL}$ on lignin content and composition are somewhat contradictory. In tobacco, a reduction of $4 \mathrm{CL}$ activity resulted in a brownish coloration of the xylem cell walls, which correlated with reductions in overall lignin levels and in cinnamyaldehyde and $S$ residues in lignin. However, values for $\mathrm{S} / \mathrm{G}$ ratio varied widely, from 0.45 to 2.0, in plants with reduced 4CL activity due 10 
large but variable reductions in $\mathrm{G}$ lignin (Kajita et al., 1996). In Arabidopsis, reduction of $4 \mathrm{CL}$ to less than $10 \%$ of wild-type activity resulted in strong reduction in $\mathrm{G}$ lignin with no reduction in $\mathrm{S}$ lignin, and it was therefore suggested that a route might exist to $S$ lignin that is independent of $4 \mathrm{CL}$ activity (Lee et al., 1997). This idea is consistent with the lack of activity of Arabidopsis $4 \mathrm{CL}$ against sinapate (Lee et al., 1997). However. sinapate is a good substrate for $4 \mathrm{CLs}$ from other species (Yamauchi et al., 2003), although a $4 \mathrm{CL}$ that accepts sinapate but not 4-coumarate has not been reported. In poplar, down-regulation of $4 \mathrm{CL}$ was reported to result in a striking decrease in lignin content with no apparent change in lignin composition (Hu et al., 1999). Interpretation of the results of $4 \mathrm{CL}$ down-regulation is difficult in the absence of complete knowledge of the full range of $4 \mathrm{CL}$ isoforms in the target organism, and their relative substrate specificities.

\section{$C C R$ and $C A D$}

Down-regulation of CCR in tobacco leads to an orange/brown xylem coloration, reductions in lignin content, and increased $S / G$ ratio due primarily to a decrease in extractable $G$ units (Piquemal et al., 1998). However, there was some variation between lines, and one line also showed a significant reduction in $\mathrm{S}$ units. These data would, therefore, be consistent with the involvement of CCR in the synthesis of both $G$ and $S$ lignin. Down-regulation of CAD in tobacco leads to lignin with an increased cinnamaldehyde content (Halpin et al., 1994; Hibino et al., 1995; Stewart et al., 1997), and increased aldehyde levels are also observed in the lignin of a loblolly pine mutant that is severely depleted in CAD (Ralph et al., 1997). It should be noted that the effects of altered CCR or CAD on S/G ratio reported to date are far less striking than the effeets of altered $\mathrm{F} 5 \mathrm{H}$ or COMT. One explanation would be that $\mathrm{F} 5 \mathrm{H}$ and $\mathrm{COMT}$ are specific for $\mathrm{S}$ lignin biosynthesis. whereas CAD and CCR are common to both $\mathrm{S}$ and $\mathrm{G}$ lignin biosynthesis.

Antisense down-regulation of CAD in transgenic alfalfa to approximately $30 \%$ of wild-type level leads to a red coloration of the stem and a reduction in S/G ratio primarily due to a decrease in $S$ units (Baucher et al. 1999). Recent studies have examined the effects of simultaneous down-regulation of both CCR and $C A D$ in transgenc tobacco (Chabannes et al., 2001; Chabannes et al., 2001). Whereas strong downregulation of CCR in tobaceo results in a phenotype characterized by dramatic structural abnormalities to xylem vessel cell walls (Piquemal et al., 1998), plants expressing both $\mathrm{CCR}$ and $\mathrm{CAD}$ transgenes had reduced lignin levels characteristic of the CCR downregulated parent line, but normal xylem cell wall morphology (Chabannes et al., 2001). These unexpected results make examination of other transgene combinations an important priority.

\section{Enzymes of one carbon metabolism}

Lignin biosynthesis exerts a high requirement on the cell for provision of one-carbon groups for the methylation reactions. The methyl group donor in lignification is S-adenosyl L-methionine (SAM), and production of this molecule occurs via a cyclical process (the active methyl cycle) in which the S-adenosyl homocysteine produced in the COMT and CCoAOMT reactions is first hydrolyzed to homocysteine which is then methylated to methionine prior to re-activation by SAM synthetase. It is interesting to note that SAM synthetase is among the most highly expressed genes in M. truncatula based on EST counts in the 40 different libraries sequenced to date. Genetic modification of SAM synthetase expression can have a profound effect on lignification. Thus, a single point mutation in the ATP binding domain of the Arabidopsis SAMS3 gene results in an approximately $35 \%$ decrease in intercellular SAM pools and a corresponding $22 \%$ decrease in lignin content (Shen et al., 2002). However, because SAM is an important methyl group donor in other cellular processes, and reductions in SAM levels result in undesirable phenotypes (Masuta et al., 1995), modification of the SAM cycle may be of limited value for lignin modification as an agronomic trait.

\section{Summary}

It is interesting that, after more than 40 years of study, our understanding of monolignol biosynthesis is still evolving. Molecular genetics and genomics approaches, coupled with advanced analytical chemistry techniques, will provide tools for obtaining an unequivocal understanding of the pathways that lead to hydroxyphenyl, guaiacyl and syringyl monolignols and their polymerization products. Important questions that still remain to be answered include:

- Does monolignol biosynthesis proceed via a grid or through linear pathways?

- How is independent regulation of $\mathrm{G}$ and $\mathrm{S}$ synthesis achieved? 
- Is there enzymatic redundancy at key steps in monolignol biosynthesis?

- Do enzyme isoforms encoded by different gene family members have independent functions?

- What is the extent and physical nature of metabolic channeling within the monolignol pathway?

\section{Acknowledgements}

Work in the authors' laboratory was funded by the Samuel Roberts Noble Foundation and grants to RAD from Forage Genetics International and the US Department of Energy.

\section{References}

Atanassova R, Favet N, Martz F, Chabbert B, Tollier MT, Monties B, Fritig B \& Legrand M (1995) Altered lignin composition in transgenic tobacco expressing $\mathrm{O}$-methyltransferase sequences in sense and antisense orientation. Plant J. 8: 465-477.

Bao W, O'Malley DM, Whetten R \& Sederoff RR (1993) A laccase associated with lignification in loblolly pine xylem. Science 260: 672-674.

Barber MS, McConnell VS \& DeCaus BS (2000) Antimicrobial intermediates of the general phenylpropanoid and lignin specific pathways. Phytochemistry 54: 53-56.

Bate NJ, Orr J, Ni W, Meroni A, Nadler-Hassar T, Doerner PW. Dixon RA, Lamb CJ \& Elkind Y (1994) Quantitative relationship between phenylalanine ammonia-lyase levels and phenylpropanoid accumulation in transgenic tobacco identifies a rate determining step in natural product synthesis. Proc. Natl. Acad Sci. USA 91: 7608-7612.

Baucher M, BernardVailhe MA, Chabbert B, Besle JM, Opsomer C, VanMontagu M \& Botterman J (1999) Down-regulation of cinnamyl alcohol dehydrogenase in transgenic alfalfa (Medicago) sativa L.) and the effect on lignin composition and digestibility. Plant Mol. Biol. 39: 437-447.

Bell C, Dixon RA, Farmer AD, Flores R, Inman J, Gonzales RA. Harrison MJ, Paiva NL, Scott AD, Weller JW \& May GD (2001) The Medicago genome initiative: a model legume database. Nucleic Acids Res. 29: 114-117.

Binns AN, Chen RH, Wood HN \& Lynn DG (1987) Cell division promoting activity of naturally occuring dehydrodiconiferyl glucosides: Do cell wall components control cell division? Proc Nat.I Acad. Sci. USA 84: 980-984.

Bolwell GP \& Butt VS (1983) Photoinduced changes in o-diphenol oxidase and p-coumarate hydroxylase activities in spinach beet seedlings and leaves. Phytochemistry 22: 37-45.

Boudet AM \& Grima-Pettenati J (1996) Lignin genetic engineering Mol. Breeding 2: 25-39.

Boudet AM, Lapierre C \& Grima-Pettenati J (1995) Tansley Review No. 80. Biochemistry and molecular biology of lignification. New Phytologist 129: 203-236.

Chabannes M, Barakate A, Lapierre C, Marita JM, Ralph J, Pean M, Danoun S, Halpin C, GrimaPettenati J \& Boudet AM (2001) Strong decrease in lignin content without significant alteration of plant development is induced by simultaneous down-regulation of cinnamoyl CoA reductase (CCR) and cimnamyl alcohol dehydrogenase (CAD) in tobacco plants. Plant J. 28: 2.57-270).

Chabannes M. Ruel K. Yoshinaga A. Chabbert B. Jauneau A. Joseleau JP \& Boudet AM (20)1) In situ analysis of lignins in transgenic tobacco reveals a differential impact of individual transformations on the spatial patterns of lignin deposition at the cellular and subcellular levels. Plant J. 28: 271-282.

Chapple CCS. Vogt T. Ellis BE \& Somerville CR (1992) An Arabidopsis mutant defective in the general phenylpropanoid pathway. Plant Cell 4: 1413-1424.

Chen F, Yasuda S \& Fukushima K (1999) Evidence for a novel biosynthetic pathway that regulates the ratio of syringyl to guaiacyl residues in lignin in the differentiating xylem of Magnolia kobus. DC. Planta 207: 597-603.

Cook D. R. (1999) Medicago trumcatula - a model in the making! Curr. Opinion Plant Biol. 2: 3()1-3()4

Cukovic D, Ehlting J. VanZiffle I \& Douglas CJ (20)1) Structure and evolution of 4-coumarate: coenzyme $A$ ligase $(+C l)$ gene families. Biol. Chem. 382: (04.5-6.54

Davin LB \& Lewis NG (1992) Phenylpropanoid melabolism: hiosynthesis of monolignols, lignans and neolignans. lignins and suberins. Rec. Adv. Phytochem. 26: 325-375.

Delay D. Dyé F. Wisniewski JP \& Delmotle F (1994) Synthesis and Agrobacterium vir-inducing activities of coniferyl alcohol $\beta$-glycosides. Phytochemistry 36: 289-298.

Dixon RA. Achnine L. Kota P. Liu C-J. M.S. R \& Wang L (20)2) The phenylpropanoid pathway and plant defense - a genomics perspective. Mol. Plant Pathol. 3: 371-39().

Dixon RA. Chen F, Guo D \& Parvathi K (20)1) The biosynthesis of monolignols: a "metabolic grid", or independent pathways to guaiacyl and syringyl units? Phytochemistry 57: 1069-1084

Dixon RA. Lamb CJ, Masoud S. Sewalt VJH \& Paiva NL (1996) Metabolic engineering: prospects for crop improvement through the genetic manipulation of phenylpropanoid biosynthesis and defense responses - a review. Gene 179: 61-71.

Ehlting J, Buttner D, Wang Q. Douglas C.J. Somssich It \& Kombrink E (1999) Three 4-coumarate: coenzyme A ligases in Arabidepsis thaliana represent two evolutionarily divergent classes in angiosperms. Plant J. 19: 9-2().

Ehlting J, Shin JJK \& Douglas CJ (200) I Ientification of 4coumarate: coenzyme A ligase (4CL) substrate recognition domains. Plant J. 27: 45.5-465.

Felton GW. Korth KL. Bi JL. Wesley SV. Huhman DV. Mathews MC. Murphy JB. Lamb C \& Dixon RA (1909) Inverse relationship between systemic resistance of plants to microorganisms and to insect herbivory. Current Biol. 9: 317-320.

Franke R, Hemm MR, Denault JW. Ruegger M(). Humphreys JM1 \& Chapple C (2002) Changes in secondary metaholism and deposition of an unusual lignin in the refs mutant of Arabidopsis Plant J. 30: 47-59.

Franke R. Humphreys JM. Hemm MR. Denault JW. Ruegger MO \& Chapple C (2002) The Arabidopsis Rl:F gene encodes the 3hydroxylase of phenylpropanoid metabolism. Plant J. 30: 3.3-4.5

Franke R. McMichael CM. Meyer K. Shirley AM. Cusumano JC \& Chapple C (2000) Modified lignin in tobaces and poplar plants over-expressing the Arabidopsis gene encoding ferulate 5-hydroxylase. Plant J. 22: 22.3-2.34

Guo D, Chen F, Inoue K. Blount JW \& Dixon RA (20()()) Downregulation of caffeic acid 3-()-methyltransferase and caffeoyl CoA 3-O-methyltransferase in transgenic alfalfa (Medicerge satica L.): impacts on lignin structure and implications for the biosynthesis of $\mathrm{G}$ and $\mathrm{S}$ lignin. Plant Cell 13: 7.3-88.

Halpin C. Knight ME. Foxon GA. Camphell MM. Boudet AM. Boon JJ. Chabbert B. Tollier MT \& Schuch W (1994) Manip- 
ulation of lignin quality by downregulation of cinnamyl alcohol dehydrogenase. Plant J. 6: 339-350.

Hibino T. Yakabe K. Kawazu T. Shibata D \& Higuchi T (1995) Increase of cinnamaldehyde groups in lignin of transgenic tobacco plants carrying an antisense gene for cinnamyl alcohol dehydrogenase. Biosci. Biotech. Biochem. 59: 929-931.

Hoffmann L. Maury S. Martz F. Geoffroy P \& Legrand M (2003) Purification, cloning, and properties of an acyltransferase controlling shikimate and quinate ester intermediates in phenylpropanoid metabolism. J. Biol. Chem. 278: 95-103.

Hu W-J. Harding SA. Lung J, Popko JL, Ralph J, Stokke DD. Tsai C-J \& Chiang VL (1999) Repression of lignin biosynthesis promotes cellulose accumulation and growth of transgenic trees. Nature Biotech. 17: 808-812.

Humphreys JM \& Chapple C (2002) Rewriting the lignin roadmap. Curr. Opinion Plant Biol. 5: 224-229.

Humphreys JM, Hemm MR \& Chapple C (1999) New routes for lignin biosynthesis defined by biochemical characterization of recombinant ferulate 5-hydroxylase, a multifunctional cytochrome P450-dependent monooxygenase. Proc. Natl. Acad. Sci. USA 96: 10045-10050.

Inoue K. Parvathi K \& Dixon RA (2000) Substrate preferences of caffeic acid/5-hydroxyferulic acid 3-O-methyltransferases in developing stems of alfalfa (Medicago sativa L.). Arch. Biochem. Biophys. 375: 175-182

Joshi CP \& Chiang VL (1998) Conserved sequence motifs in plant S-adenosyl-L-methionine-dependent methyltransferases. Plant Mol. Biol. 37: 66.3-674.

Jouanin L. Goujon T, deNadai V. Martin MT, Mila I. Vallet C. Pollet B. Yoshinaga A. Chabbert B. PetitConil M \& Lapierre C (2000) Lignification in transgenic poplars with extremely reduced caffeic acid O-methyltransferase activity. Plant Physiol. 12.3: 1.36.3-1.373.

Kajita S, Katayama Y \& Omori S (1996) Alterations in the biosynthesis of lignin in transgenic plants with chimeric genes for 4-coumarate: Coenzyme A ligase. Plant Cell Physiol. 37: 957-965.

Knobloch KH \& Hahlbrock K (1975) Isoenzymes pf p-coumarate: CoA ligase from cell suspension cultures of Glycine max. Eur. J. Biochem. 52: $311-320$

Lam TBT, liyama K \& Stone BA (1996) Caffeic acid: $O$ methyltransferases and the biosynthesis of ferulic acid in primary cell walls of wheat seedlings. Phytochemistry 41: 1507-1510.

Lee D \& Douglas CJ (1996) Two divergent members of a tobacco 4coumarate:coenzyme A Ligase (4CL) gene family. Plant Physiol. 112: 193-2205

Lee D. Meyer K. Chapple C \& Douglas CJ (1997) Antisense suppression of 4-coumarate:coenzyme A ligase activity in $\mathrm{Ar}$ abidopsis leads to altered lignin subunit composition. Plant Cell 9: 1985-1998.

Lewis NG. Davis LB \& Sarkanen S (1999) The Nature and Function of Lignins. In: Comprehensive Natural Products Chemistry. Vol. 3. DHR Barton \& K Nakanishi (eds) (pp. 617-745.) Elsevier. Oxford.

Li L. Cheng XF. Leshkevich J. Umezawa T. Harding SA \& Chiang VL (2001) The last step of syringyl monolignol biosynthesis in angiosperms is regulated by a novel gene encoding sinapyl alcohol dehydrogenase. Plant Cell 13: 1567-1585.

Li L. Popko JL. Umezawa T \& Chiang VL (2000) 5Hydroxyconiferyl aldehyde modulates enzymatic methylation for syringyl monolignol formation, a new view of monolignol biosynthesis in angiosperms. J. Biol. Chem. 275: 6537-6545.

Li L. Popko JL. Zhang X-H. Osakabe K. Tsai C-J, Joshi CP \& Chiang VL (1997) A novel multifunctional $O$-methyltransferase implicated in a dual methylation pathway associated with lignin biosynthesis in loblolly pine. Proc. Natl. Acad. Sci. USA 94: 5461-5466.

Maher EA, Bate NJ, Ni W, Elkind Y, Dixon RA \& Lamb CJ (1994) Increased disease susceptibility of transgenic tobacco plants with suppressed levels of preformed phenylpropanoid products. Proc. Natl. Acad. Sci. USA. 91: 7802-7806.

Marita JM, Ralph J, Hatfield RD \& Chapple C (1999) NMR characterization of lignins in Arabidopsis altered in the activity of ferulate 5-hydroxylase. Proc. Natl. Acad. Sci. USA 96: 12382-12332.

Marita JM. Ralph J, Hatfield RD, Guo D, Chen F \& Dixon RA (2002) Structural and compositional modifications in lignin of transgenic alfalfa down-regulated in caffeic acid 3O-methyltransferase and caffeoyl CoA 3-O-methyltransferase. Phytochemistry 62: 53-65.

Martin C \& Paz-Ares J (1997) MYB transcription factors in plants. Trends Genet. 13: 67-73.

Masuta C, Tanaka H, Uehara K, Kuwata S, Koiwai A \& Noma $M$ (1995) Broad resistance to plant viruses in transgenic plants conferred by antisense inhibition of a host gene essential in Sadenosylmethionine-dependent transmethylation reactions. Proc. Natl. Acad. Sci. USA 92: 6117-6121.

Matsui N, Fukushima K, Yasuda S \& Terashima N (1994) On the behavior of monolignol glucosides in lignin biosynthesis. Holzforschung 48: 375-380.

Maury S, Geoffroy $\mathrm{P} \&$ Legrand $\mathrm{M}$ (1999) Tobacco $O$ methyltransferases involved in phenylpropanoid metabolism. The different caffeoyl-coenzyme A/5-hydroxyferuloylcoenzyme A 3/5-O-methyltransferase and caffeic acid/5-hydroxyferulic acid 3/5-O-methyltransferase classes have distinct substrate specificities and expression patterns. Plant Physiol. 121: 215-223.

Mazur W \& Adlercreutz H. (1998) Naturally occurring oestrogens in food. Pure Appl. Chem. 70: 1759-1776.

Meyer K, Shirley AM, Cusumano JC, Bell-Lelong DA \& Chapple C (1998) Lignin monomer composition is determined by the expression of a cytochrome P450-dependent monooxygenase in Arabidopsis. Proc. Natl. Acad. Sci. USA 95: 6619-6623.

Neish AC (1968) Monomeric intermediates in the biosynthesis of lignin. In: K Freudenberg \& AC Neish (eds) Constitution and Biosynthesis of Lignin. (pp. 2-43). Springer-Verlag, Berlin.

$\mathrm{Ni}$ W, Paiva NL \& Dixon RA (1994) Reduced lignin in transgenic plants containing an engineered caffeic acid $\mathrm{O}$-methyltransferase antisense gene. Transgenic Res. 3: 120-126.

O Connell A. Bolwell P \& Schuch W (1998) Impact of forest tree biotechnology on the pulp and paper-making processes in the 2 Ist century. In: K Lindsey (ed) Transgenic Plant Research. (pp. 175-186.) Harwood Academic Publ, Chur.

Osakabe K, Tsao CC, Li L, Popko JL, Umezawa T, Carraway DT, Smeltzer RH, Joshi CP \& Chiang VL (1999) Coniferyl aldehyde 5-hydroxylation and methylation direct syringyl lignin biosynthesis in angiosperms. Proc. Natl. Acad. Sci. USA 96: 8955-8960.

Parvathi K, Chen F, Guo D, Blount JW \& Dixon RA (2001) Substrate preferences of $O$-methyltransferases in alfalfa suggest new pathways for 3-O-methylation of monolignols. Plant J. 25: 193-202.

Piquemal J, Chamayou S, Nadaud I, Beckert M, Barriere Y, Mila I, Lapierre C, Rigau J, Puigdomenech P, Jauneau A, Digonnet C, Boudet A-M, Goffner D \& Pichon M (2002) Down-regulation of caffeic acid $O$-methyltransferase in maize revisited using a transgenic approach. Plant Physiol. 130: 1675-1685. 
Piquemal J, Lapierre C, Myton K, O`Connell A, Schuch W, GrimaPettenati J \& Boudet AM (1998) Down-regulation of cinnamoylCoA reductase induces significant changes of lignin profiles in transgenic tobacco plants. Plant J. 13: 71-83.

Quackenbush J, Liang F, Holt I, Pertea G \& Upton J (2000) The TIGR gene indices: reconstruction and representation of expressed gene sequences. Nucleic Acids Res. 28: 141-145.

Rae AL, Manners JM, Jones RJ, McIntyre CL \& Lu DY (2001) Antisense suppression of the lignin biosynthetic enzyme, caffeate O-methyltransferase, improves in vitro digestibility of the tropical pasture legume, Stylosunthes humilis. Australian J. Plant Physiol. 28: 289-297.

Ralph J, MacKay JJ, Hatfield RD, O'Malley DM, Whetten RW \& Sederoff RR (1997) Abnormal lignin in a loblolly pine mutant. Science 277: 235-239.

Rasmussen S \& Dixon RA (1999) Transgene-mediated and elicitorinduced perturbation of metabolic channeling at the entry point into the phenylpropanoid pathway. Plant Cell 11: 1537-1551.

Sato Y, Sugiyama M, Górecki RJ, Fukuda H \& Komamine A (1993) Interrelationship between lignin deposition and the activities of peroxidase isoenzymes in differentiating tracheary elements of Zinnia. Planta 189: 584-589.

Schoch G, Goepfert S, Morant M, Hehn A. Meyer D, Ullmann P \& Werck-Reichart D (2001) CYP98A3 from Arabidopsis thaliana is a $3^{\prime}$-hydroxylase of phenolic esters, a missing link in the phenylpropanoid pathway. J. Biol. Chem. 276: 36566-36574.

Sewalt VJH, Ni W, Blount JW, Jung HG, Howles PA, Masoud SA, Lamb C \& Dixon RA (1997) Reduced lignin content and altered lignin composition in transgenic tobacco down-regulated in expression of phenylalanine ammonia-lyase or cinnamate 4-hydroxylase. Plant Physiol. 115: 41-50.

Shen B, Li C \& Tarczynski MC (2002) High free-methionine and decreased lignin content result from a mutation in the Arabidopsis $S$-adenosyl-L-methionine synthetase 3 gene. Plant J. 29 371-380.

Stewart D, Yahiaoui N, McDougall GJ. Myton K, Marque C, Boudet AM \& Haigh J (1997) Fourier-transform infrared and Raman spectroscopic evidence for the incorporation of cinnamaldehydes into the lignin of transgenic tobacco (Nicotiana tabacum L.) plants with reduced expression of cinnamyl alcohol dehydrogenase. Planta 201: 311-318.

Tamagnone L, Merida A, Parr A, Mackay S, Culianez-Macia FA, Roberts K \& Martin C (1998) The AmMYB308 and AmMYB330 transcription factors from antirrhinum regulate phenylpropanoid and lignin biosynthesis in transgenic tobacco. Plant Cell 10: 135-154.

Terashima N, Fukushima K, He L-F \& Takabe K (1993) Compre- hensive model of the lignified plant cell wall. In: HG Jung. DR Buxton, RD Hatfield \& J Ralph (eds) Forage cell wall structure and digestibility. ASA-CSSA-SSSA. Madison. pp. 247-270.

Tsai CJ. Popko JL, Mielke MR, Hu WJ. Podila GK \& Chiang VL (1998) Suppression of ()-methyltransferase gene by homologous sense transgene in quaking aspen causes red-brown wood phenotypes. Plant Physiol. 117: 101-112

Ulbrich B \& Zenk MH (1979) Partial purificaltion and properties of hydroxycinnamoyl-CoA: quinate hydroxycinnamoyl transferase from higher plants. Phytochemistry 18: 929-93.3.

Urao T, Yamaguchi-Shinozaki K. Urao S \& Shinozaki K (1993) An Arabidopsis myb homolog is induced by dehydration stress and its gene product binds to the conserved MYB recognition sequence. Plant Cell 5: 1529-15.39.

Van Doorsselaere J, Baucher M. Chognot H. Chabbert B. Tollier M-T. Petit-Conil M. Leplé J-C. Pilate G. Cornu D. Monties B. Van Montagu M. Inzé D. Boerjan W \& Jouanin L (1995) A novel lignin in poplar trees with a reduced caffeic acid/5. hydroxyferulic acid ()-methyltransferase activity. Plant J. 8 : 855-864.

Vignols F, Rigau J, Torres MA. Capellades M \& Puigdoménech P (1995) The brown midrib3 (bm3) mutation in maize occurs in the gene encoding calfeic acid O-methyltransferase. Plant Cell 7: $407-416$

Vincent JR \& Nicholson RL (1987) Evidence for isoenzymes of 4-hydroxycinnamic acid: CoA ligase in maize mesocotyls and their response to infection by Helminhosporrum madis race () Physiol. Mol. Plant Pathol. 30: 121-129

Wesley VS. Helliwell CA. Smith NA. Wang MB. Rouse DT. Liu Q, Gooding PS, S.P. S. Abbott D. Stoutjesdijk PA. Robinson SP, Gleave AP, Green AG \& Waterhouse PM (20)1) Construct design for efficient. effective and high-throughput gene silencing in plants. Plant J. 27: 581-590)

Whetten $R$ \& Sederoff $R(1991)$ Genetic engineering of wood. For Ecol. Manage. 43: 301-316.

Yamauchi K. Yasuka S. Hamada K. Tsutsumi $S \&$ Fukushima K (2003) Multiform biosynthetic pathway of syringl lignin in angiosperms. Planta 216: 496-5()1

Ye ZH. Kneusel RE. Matern U \& Varner JE (1994) An alternative methylation pathway in lignin hiosynthesis in Zimnia. Plant Cell 6: 1427-1439.

Zhong R. Morrison I. W.H.. Negrel J \& Ye ZH (1998) Dual methylation pathways in lignin biosynthesis. Plant Cell 1(): 2033-2045

Zubieta C. Kota P. Ferrer J-L. Dixon RA \& Noel J (20)2) Structural basis for the modulation of lignin monomer methylation by caffeic acid/5-hydroxyferulic acid 3/5-()-methyltransferase. Plant Cell 14: 1265-1277. 